\title{
A Conceptual Study on Role Stressors, their impact and Strategies to manage Role Stressors
}

\author{
${ }^{1}$ Mrs. Shruti Trayambak, ${ }^{2}$ Dr Pranab Kumar, ${ }^{3}$ Dr A.N Jha \\ ${ }^{I}$ (Research Scholar, Department of Management, BITEC Lalpur ,India ) \\ 2 ( Assistant Professor Department of Management, BITECH Lalpur, India) \\ ${ }^{3}$ ( Professor, Department of Management, BITEC Lalpur,India )
}

\begin{abstract}
Role stressors are highly inevitable in nature and have become major concern at workplace .The main objective of this paper is to study the concept of role stressors and their relationship with job stress and job satisfaction. Number of studies found that there is positive relationship between role stressors and job stress and negative relationship between job stress and job satisfaction. But some researchers found no such relationship between role ambiguity and role conflict with job satisfaction.This paper also discussed measuring tools and management tools for role stress variables.
\end{abstract}

Key words: Role stressors, Role conflict, role ambiguity, role overload, job stress, job satisfaction.

\section{Introduction:}

The concept of stress was first proposed by Hans Selye (1936). According to Selye (1974), stress, is "the nonspecific response of the body to any demand made upon it". Stress is broader in term and to define stress is very difficult. Due to its complex nature most of the researchers cannot agree on a single definition ( Kahn \& Boysiere ,1992). Stress can be a motivator and get the job done .Some stress researchers ( e.g Golembiewski, Munzernider and Stewenson ,1986; Sharahan and Mortimer ,1996), distinguish between negative stress ,termed 'distress 'and positive stress, termed 'eustress'. This "good stress" or 'eustress 'can be defined as is actually a positive and healthy form of stress and some people enjoy it .Eustress activates and motivates people to accomplish goal. The "Distress" is when the good stress becomes too much to bear or cope with. It is important to note that there are three levels of stress -low level, moderate or optimal level and high level. Moderate or Optimal level of stress may acts as a motivator. On the basis of literature survey it is clearly understood that too much stress is toxic to employees and too little stress can also lead unexpected problem. For example too little stress can result in boredom \& apathy and can be accompanied by low performance and too much stress can cause depression, dissatisfaction, anxiety, tension and low performance. An optimal level of stress results in high energy, motivation and high performance.The cause or source of stress is known as "stressors "\& stressors are conditions and events that evoke strain (Kahn \& Byosiere, 1992). According to Cooper \& Marshall (1978) sources of managerial stress can be categorized into six components -intrinsic to job , role in organization , career development, organizational structure and climate, relationship within organization and organizational interface and outside .Matteson \& Ivancevic (1999) and Cook \& Hunsaker (2001) identified that stress can be caused by environmental, organizational, and individual variables. Kahn et al ( 1964) conducted a series of studies which is based on Institute of Social Research (ISR) and found role conflict and role ambiguity are source of job stress . Role overload or workload is the third form of role stress and it can be defined as a number of tasks assigned to perform more than individual's capabilities, time pressures as well as scarcity of resources to fulfill commitment (Beehr \& Glazer, 2005). Role stress variables that consist of role conflict, role ambiguity and role overload belong to organizational variables. According to Ivancevich \& Matteson (1980) and French Caplan \& Harrison (1982), role ambiguity and role conflict have been identified as a major source of stress and job tension. Other than these two stressors, work overload both quantitatively and qualitatively has been empirically linked to a variety of physiological, psychological and behaviour strain symptoms (Beehr \& Newman, 1978; Roberts et al., 1997; Miller \&Ellis, 1990). A number of researchers ( Fisher and Gitelson, 1983; Jackson and Schuler, 1985;Van Sell et al., 1981; Lee, 1997; Jones, 1993) found that role stressors are responsible for creating negative impacts such as job tension, job dissatisfaction,employee turnover ,employee burnout, low organizational commitment and performance (Johnson et al., 1990; Jackson and Schuler, 1985).Therefore, managers should identify these variables to manage role stress at workplace

\section{Objectives Of The Study}

1) To study the concept of role stressors and their relationship with job stress and job satisfaction.

2) To identify the effects of job stress on job satisfaction.

3) To identify appropriate tools to manage role stressors. 


\section{Methodology}

This study is a descriptive study to find the role stressors among the employees for any organization. The data has been collected from various secondary data sources. The various sources that has been explored for the study are books , magazines ,journals ,e-journal, published research papers and dissertations.

\section{Literature Review}

The term role can be defined as an expected mode of behaviour. Kahn et al ( 1964) and Kartz and Kahn ( 1978) defined role as an interaction between role sender and role incumbent .Role sender sends expectation to role incumbent who has a specific position within an organization. There are three types of roles (i) the expected role, (ii) the perceived role and (iii) the actual role. The expected role is what other people expect from an individual. The perceived role is how the individual thinks he or she should behave to fulfil the expected role and the actual role is the way the person actually behaves in the organization.

Role stressors or role stresses are anything about an organizational role that creates negative consequences for employees ( Kahn and Quinn,1970). Role related stress are concerned with how individuals perceive the expectations others have of them and includes role ambiguity and role conflict ( Alexandros Stamatios et. al.,2003) .According to Schafer (1998) role stressors are "associated with social roles, which are social positions with clustered expectations". Role stressors are made-up of three variables: role conflict, role ambiguity \& role overload. The major role stress variables are taken into considerations for study are-role conflict, role ambiguity and role overload/work overload .Role conflict can be defined as when individuals simultaneously perform multiple roles and they conflict each other. Drafte (1998) defined role conflict "job roles that interfere with on another" and Schafer (1998) defined "incompatible expectations associated with a social position, such as student, employee, or mother". Kahn et al (1964) have defined role conflict existence of two or more roles such that to manage with one would make difficult to manage with other. They identified five major forms of role - first one is intrasender conflict that occurs when a role set member requires the focal person to perform contradictory .For example a role sender may request the role incumbent to perform task and task cannot be completed without disturbing rules. But role Sender attempts to enforce the rule, second is intersender conflict that occurs when the role behaviour demanded by one role set members incompatible with the role behaviour demanded by another role set members, third is interrole conflict which occurs when the focal person receives two or more role at times which are incongruence in nature,fourth is intrarole conflict or person -role conflict which occurs when the role requirements are incongruent with the focal person's attitudes , values and profession behaviour and the last is role overload which occurs $\mathrm{s}$ when the focal person is required to do number of tasks by different role set members. Role ambiguity arises when individual do not have role clarity to perform the assigned job (Rizzo, House \& Lirtzman, 1970; Ivancevich \& Matteson, 1980; Ashforth \& Lee, 1990;Kahn et al ,1964). Individual's having unclear plans and objective ,lack of clarity of one's duty and uncertainty about the amount of authority to perform assignment ( Rizzo et al ,1970) . A person is likely to experience two types of role ambiguity. One, concerning the task and the related activities; the other concerning the feedback regarding his performance of the task. For example in case of academics, lack of regular feedback from their leaders was the highest source of stress ( Dua;1994 \& Sharpley et al.1996). Regular and quality feedback enforce the academics to analyze their performance on the job, if he or she is going on right direction or not. Quality and positive feedback may result in high performance and low stress among academics. According to Bandura \& Locke, (2003) who do not receive regular feedback may experience considerable uncertainty about their role performance. Regular feedback from a supervisor may reduce role ambiguity. Role overload is a complex form of role conflict. Kahn et al (1964) identified role overload and it occurs simply when employees have more task than he or she can handle. When a set role expectations are higher than the focal person's capabilities resulted in role overload.It can be either qualitative \& quantitative Quantitative task can be defined as the person has too many tasks to perform or too little time to perform them and Qualitative occurs when person lacks ability to perform task . For example academics experience role overload (Dua, 1994; Gillespie et al., 2001; Taris et al., 2001) because they generally face difficulty in completing their assigned tasks due to work overload (Giliespie et al., 2001) especially new academic members.. This finding is consistent with prior research (Gmelch et al., 1984; Dua, 1994; Sharpley, Reynolds, Acosta \& Dua, 1996). Lease (1999) reported this is a significant predictor of strain.

Stress models such as the ISR model (Institute of Social Research) or the Role Stress Approach, Cooper et al ( 2001) stress model and Cooper and Marshall's ( 1976) stress model found that role stressors are major source of job stress and job stress negatively affects job satisfaction. There is evidence that job stress affects job satisfaction negatively and there is significant relation between these two .According to Igharia and Greenhaus (1992) ,job stress affects job satisfaction and career satisfaction negatively. Stamps \& Piedmonte ( 1986) found significant relationship between job stress and job satisfaction.Researchers cited positive relationship between role stressors and job stress. Rosenheim (1976) found that anxiety is directly related to role conflict, role ambiguity and role overload. A number of researchers also demonstrated that role conflict is associated with low job involvement \& organizational commitment, tension, anxiety \& intention to leave 
organization (Behrman \& Perrault ,1984; Brief and Aldag ,1976; Fisher \& Gitelson ,1983;House \& Rizzo 1972;Jackson \& Schuler ,1985;Johnson \& Stinson ,1975;Miles,1975;Miles and Perrault 1976; Rizzo at al ,1976; Sohi ,1996).Role ambiguity is also responsible for job stress and job dissatisfaction( House \& Rizzo,1972; Hamner \& Tosi, 1974; Ivancevich \& Donnelly, 1974; Wright \& Thomas, 1982; Cordes \& Dougherty, 1993) . Fisher and Gitelson ( 1983) , Jackson and Schuler ( 1985), Van Sell et al ( 1981), Lee ( 1997) and Jones ( 1993) identified that role conflict \& role ambiguity are responsible for job tension, job dissatisfaction , employee turnover and employee burnout. Keenan and McBain (1979) found positive relationship between tension and role overload. Batesman (1981) in his study, reported that role overload resulted in poor job satisfaction. But there are exceptions in a study of relationship between role conflict and role ambiguity with job satisfaction. Hamner and Tosi (1974) reported no relationship between role conflict and job satisfaction in a study among a sample of managers. They reported a positive correlation between role conflict and job threat among a sample of managers.Tosi and Tosi (1970) found a negative relationship between role conflict and job related threat and anxiety. Keller (1975) observed negative relationship between role conflict and job satisfaction among researchers but no such negative relationship among development professionals. The observation suggests the effects of role conflict vary with various occupations. Studies had shown a difference in the impact of role ambiguity across occupations. According to Beehr et al. 1976; Caplan et al. 1975; Greene 1972; Hamner \& Tosi, 1974; Johnson \& Stinson 1975; Paul 1974;: Rizzo et al. 1970 ,found that role ambiguity is positively associated with job dissatisfaction but studies among nurse's aides (Brief \& Aldag, 1976), managers (Tosi, 1971) ,teachers (Tosi \& Tosi, 1970) and supervisors and operating employees, (Ivancevich\& Dobbelly, 1974) found no such relationship.

On the basis of above literature review conceptual framework of role stressors can be designed:

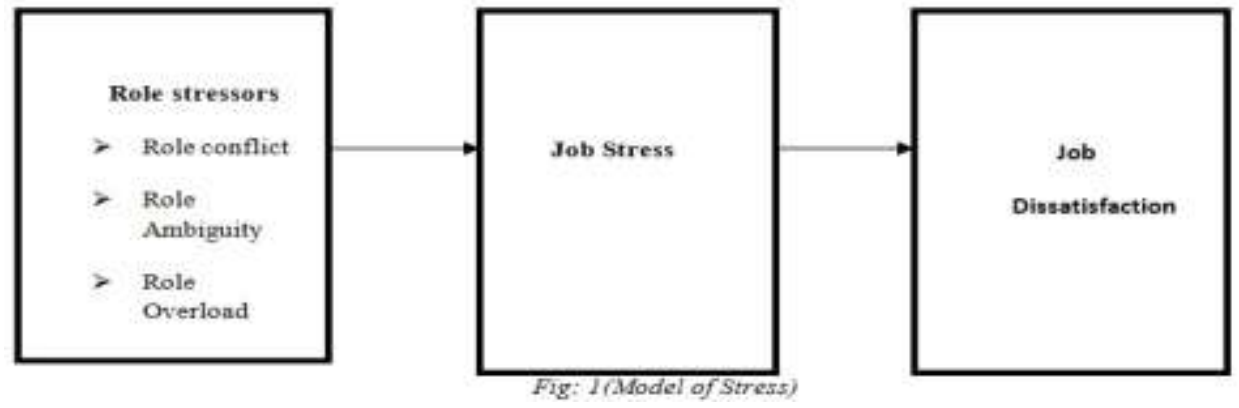

Managers can play a vital role in identifying and tacking role stressors .They should also investigate their consequences experienced by employees. For example employee experiences role overload when he or she would be assigned a number of tasks more than his or her capabilities from different managers. In this case, role overload could be managed by assigning optimal workload from his or her managers sub-ordinates or leaders.

\section{Managing Role Stress Variables:}

In highly competitive environment, firstly organizations and their employees should become aware of role stress variables and which they must seek to reduce or manage the variables if their organizations are to survive and grow. Secondly measuring role stress variables, identifying sources of stress and reducing those stress variables. For example either role ambiguity or role conflict or role overload could be a source of stress. Managers or employers or role senders or mentors can play an important role in reducing sources of role stress variables There are various tools and techniques are available to measure role stress variables such as Rizzo et al scale(1970) or RHL scale ,Organization role stress ( ORS) scale, Spector and Jex $\square$ s (1998) Quantitative Workload Inventory (QWI), The Role Ambiguity Scale (RAS; Beauchamp et al., 2002) etc. According to Jackson and Schuler (1985), 85\% of researchers use the 6-to-12-item scale RHLscale. This scale captures onedimensional ambiguity perceptions about the overall or global ambiguity associated with one's role. The first scale developed by Rizzo et al. (1970) to measure role conflict and role ambiguity and has been widely used by researchers.

\section{MENTORING:}

Mentoring is one of the effective tool to manage role stress at workplace .According to Hunt \& Michael, (1983) mentors are highly experienced person in organization who is interested in guiding and promoting individual's career and also members of that role set. Kahn et al, concluded from their study that role incumbent experiences low job satisfaction, lower confidence in organization, high degree of tension \& intention to quit organization due to role expectations are not clear to the focal person or focal person's perceived role not matches with expected role. Here mentors can provide role clarifying information to the focal person and alternatives for dealing with role demands including role expectation that may create conflict. 
A Conceptual Study on Role Stressors, their impact and Strategies to manage Role Stressors

According to Griffin ( 1992) suggest that role ambiguity occurs because a person is not clear about her or his role or there is no proper communication between role set members and the focal person. Sawyer, 1992 found that quality feedback from role set members or supervisors and co-workers is responsible to minimize role ambiguity. For example academics experience role ambiguity due to lack of regular feedback which is highest source of stress ( Sharpely et al 1990) According to Major, Kozilowski, Chao \& Gardner (1995), intentions to leave organization can be minimized by high quality exchange between leaders and sub-ordinates. Brown and Peterson (1993) conducted meta-analytical study and found role conflict and role ambiguity affect employee satisfaction in negative way. But according to Chao . Wartz \& Gardener ,(1992) and Whitely \& Coetsier (1993) mentoring can result in higher job satisfaction.

\section{Role Episode Model:}

Role episode model is known as interactional management tool between Role Set Members \& Role Incumbent given by Katz and Kahn (1978). In order to examine and integrate the research on role conflict and ambiguity, Khan et al. role episode model is very useful. The model depicts transactional relationship between role senders and focal person. Focal person or role incumbent occupies a particular position (social location) within organization. Individuals who send role expectation to the focal person regarding his or her activities in the role compromise role set (Merton 1957). They are called role senders or Role Set Members. When Role Set Members communicated their expectations are called sent role carries role pressure .The set of expectations ,a role incumbent or focal person receive from Role Set Members. The role episode model consists of a cyclic series of communications between Role Set Member and the Role Incumbent. This process continues until the role episode finishes, creates shared expectations or postpone negotiations. Fig 2. suggests that there are organizational, personal, and interpersonal factors which affect the role episode model. The organizational factors consist structure, level in the organization, role requirements, task characteristics, physical setting, and organizational practices. The personal factors (which can be applied to both the role senders and focal person) refer to such variables age, sex, and tenure in the organization. The interpersonal factors in the relationship between role senders and focal person include frequency of their interactions, mode of communication, importance of senders to focal person,physical location, visibility, feedback and participation. The role senders can be the focal person's supervisors, clients, co-workers, or subordinates in the organization. Role sender focal person relationship have generally been investigated by gathering perceptual data on role conflict and ambiguity from the objective responses. Kahn et al (1964) found found lower levels of job satisfaction for those with high role conflict and ambiguity. Rizzo et al (Rizzo, House, and Lirtzman, 1970) found the same thing and supported the Kahn et al theory. This model is used by various researchers to identify predictors associated with role stress in order to reduce stress which can increase job satisfaction among employees because job stress affects job satisfaction negatively ( Igharia and Greenhaus (1992).

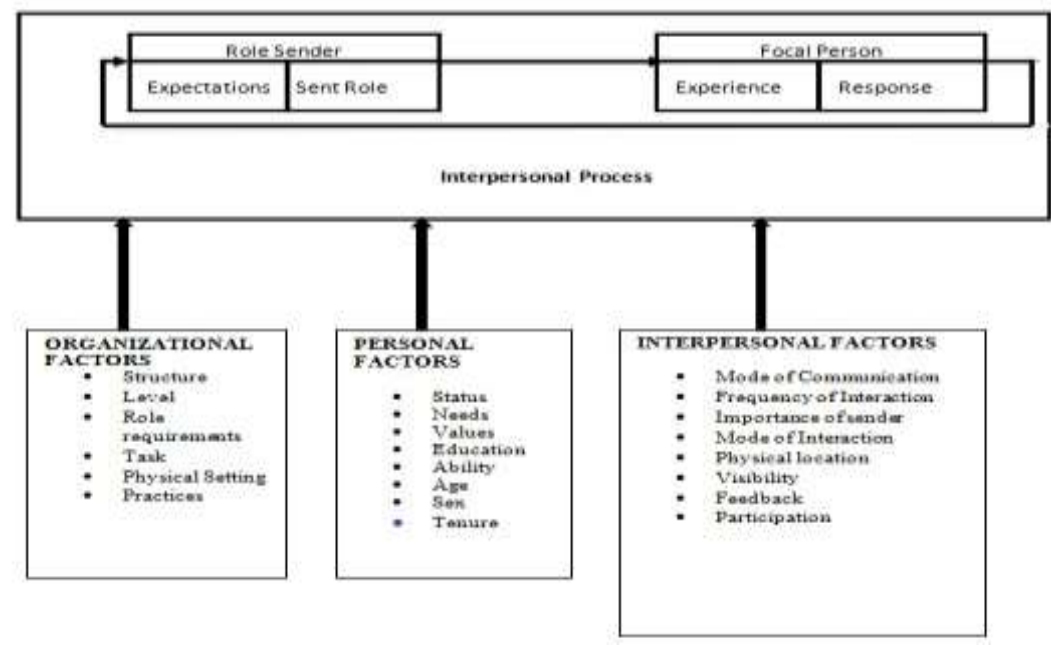

Fig: 2 Kahn et al's Role Episode Model.

Source: Van Sell et al (1981),http://www.scribd.com/doc/54672002/13/THE-ROLE-EPISODE-MODEL

It can be summarized that role episode model is one of the most suitable model to manage role stress variables. Rationale for choosing this model:

i) Role episode model( Kahn et al ,1964) based on role theory and is most suitable model to explain variables related to role conflict and role ambiguity .

ii) It is widely used by researchers to study role stress variables among workers (Schuler, 1975; Fisher \&Gitelson ;1973) 
iii) It is efficient tools to identify predictors involved in role stress variables.

iv) According to Doughtery and Pitchard ,1985, the role conflict and role ambiguity measurement captured somewhat global perception of role stress and can be used with any job.

v) It is management interactional tool.

vi) It offers a way to focus on manager's communication uniquely in the field.

vii) It captures role dynamics and easily integrates into managerial work, jobs and behaviour perspective.

\section{CONCLUSION:}

Role stressors are responsible for job stress and job dissatisfaction. Contradictory findings were obtained by some researchers in relationship between role conflict and role ambiguity with job satisfaction. Some researchers found no such relationship between role conflict and role ambiguity with job satisfaction among nurse's aides, managers, teachers, supervisors, operating employees, research and development professionals. There are various tools and techniques to measure and manage role stressors and among those, Kahn et al's role episode model is one of the classical tools to study and to manage role stressors at workplace.

\section{Books}

\section{References:}

[1] Green Early . Leadership Expectations How executive expectations are created and used in a Non Profit Setting ( Paternoster 2005).

[2] M.Afzabur Rahim. Managing Conflicts in Organization (Transactional publishers New Brunswick New Jersey 2001).

[3] RobertL.Kahn Organizational Stress: Studies in Role Conflict and Ambiguity . John Wiley \& Sons Inc1964).

\section{Journals:}

[4] Faridah Ibrahim : Predictors of Role Stress Among Malaysian Journalist in Newsroom Decision -Making Process. Jurnal Komunikasi ; Malaysian Journal of Communication 2001, 17 . pp. 119-137.

[5] Arthur G.Bedeian, Achilles A.Armenakis \& Shirley M.Curran .Personality Correlates of Role stress .Psychological Reports, 1980,46,627-632.

[6] Cynthia LeRouge, Anthony Nelson \& J.Ellis Blanton .The Impact of role stress fit and Self-Esteem on the job attitudes of IT Professional .Information \& Management,2006, 43 928-938.

[7] Cynthia Lee, Susan J.Ashford \& Linda F.Jamileson.The effects of Type A behaviour Dimensions and optimism on coping strategy, health, and performance .Journal of Organizational behaviour,1993, Vol.14, 143-157.

[8] Cynthia Lee.The relations of personality and cognitive styles on Job and class Performance. Journal of Organizational Behaviour ,1992,Vol.13, $175-185$.

[9] Carly S.Bruck and Tammy D.Allen .The relationship between big five personalitytraits, negative affectivity , type A behaviour ,and work-family conflict . Journal ofVocational Behaviour,2003 63 (457-472).

[10] Dieter Zapf, Christian Dormann and Michael Frese .Longitudinal studies in Organizational Stress Research: A Review of the Literature with Reference to Methodological Issues .Journal of Occupational Health Psychology, 1996, Vol.1, No.2, $145-169$.

[11] Debograh Manning and April Preston . Organizational Stress: Focussing on ways to Minimize Distress CUPA -HR Journal, Summer ,2003,Vol. 54 No.2.

[12] Erika Kirby and Kathleen J.Krone .The Policy exists but you cannot really use it: Communication and the structuration of workfamily policies by .Journal of Applied Communication Research,2002, Vol.30, No.1, pp50-77.

[13] Mrs Rumi Dasgupta and Dr.Amishi Arora.Analysis of work life Balance ( A study of the targeted corporate sectors in and around Nagpur with a small number of samples) International journal of Research ibn IT \& Management,2011, Vol1,Issue 8

[14] Naikoi Atsumi .Work-Life Balance strategies for advanced companies .Japan Labour Review 2007,vol.4,no.4 .

[15] Nilufar Ahsan,Zaini Abdullah,David Yong Gun Fie \&Syed Shah Alam .A study of Job stress on Job Satisfaction among University staff in Malaysia :Empiricalstudy. European Journal of Social Sciences -Volume 8, European Journal of SocialSciences -2009, Volume 8, Number 1. 121.

[16] NiMuttie ur Rehman ,Rabbia Irum , Namra Tahir ,Zara Ijaz ,Uzma Noor ,Ume Salma.The Impact Of Job Stress on Employee Job Satisfaction :A Study on Private Colleges Of Pakistan .Journal Of Business Studies Quarterly,2012, Vol.3, No.3, pp.

[17] 50-56

[18] Nicole Conrad \& Marc Party .Conscientiousness and Academic Performance: A Mediational Analysis .International Journal of the Scholarship of Teaching and Learning .2012,Vol.6, No.1.

[19] O, Ojokuku ,R.M \& Ileasenami O.A O Impact of Job Stress on Manager's Performance .European Journal of Scientific Research 2010,ISSN, Vol.45 No.2 pp.249-260)

[20] Rob peace.Article Review: Personality assessment in Organisational settings .Griffith University Undergraduate student Psychology Journal ,2001, Volume 1.

[21] Sethela June1 and Rosli Mahmood..The Relationship between Role Ambiguity, Competency and Person -Job Fit With the Job Performance of Employees in the Service Sector SMEs in Malaysia. Business Management Dynamics ,2011,Vol .1, No.2pp.79-98.

[22] Yung-Tai Tang and Chen -Hua Chang .Impact of role ambiguity and role conflict on Employee creativity .African Journal of Business Management ,2010,Vol.4 (6).pp.869-881.

[23] Hussain S, Ghaffar A, Aslam . Biological control of Macrophomina phaseolina charcoal rots of sunflower and mung bean. Egypt J. Phytopathol.1990,130: 157-160. 